Tropical Journal of Pharmaceutical Research November 2016; 15 (11): 2399-2405

ISSN: $1596-5996$ (print); 1596-9827 (electronic)

(C) Pharmacotherapy Group, Faculty of Pharmacy, University of Benin, Benin City, 300001 Nigeria.

All rights reserved.

Available online at http://www.tjpr.org

Original Research Article

http://dx.doi.org/10.4314/tjpr.v15i11.14

\title{
Effect of ginseng root polysaccharides on cutaneous wound repair in mice
}

\author{
Li-Ying Fan ${ }^{1,2}$, Te Guo ${ }^{1}$, Jun Ren ${ }^{3}$, Yi-Fa Zhou ${ }^{1 *}$ \\ ${ }^{1}$ School of Life Sciences, Northeast Normal University, ${ }^{2}$ Life Science and Technology Institute, Changchun University of \\ Science and Technology, ${ }^{3}$ Research Institute of Forest, Jilin Provincial Academy of Forest Science, Changchun, PR China \\ *For correspondence: Email: Zhouyf383@nenu.edu.cn; Tel: +86-43185098212
}

\begin{abstract}
Purpose: To evaluate the healing activity of water ginseng (Panax ginseng C.A. Meyer) polysaccharide (WGP) in vivo.

Methods: Mice were divided into four groups: group 1 was the control, and groups 2-4 were treated with WGP (15 mg or $30 \mathrm{mg}$ ) or mouse epidermal growth factor (mEGF, $0.1 \mathrm{~mL}, 2000 \mathrm{IU} / \mathrm{mL}$ ), respectively. Full-thickness excision wounds were made on the back of each mouse. Wound areas were imaged, and wound contraction (\%) was calculated. Histological observation and analysis of collagen content were performed using standard biochemical methods.

Results: Wound contraction and the period of epithelialization in WGP groups were significantly different from those of control. The $30 \mathrm{mg}$ WGP group showed $85.0 \%$ wound healing, while control group showed only $65.8 \%$ wound healing $(p<0.001) 10$ days after the operation. WGP also promoted the formation of collagen in a dose-dependent manner. Histological examination confirmed that fibroblasts and new blood vessels were more abundant in WGP group than in control group.

Conclusion: Topical application of WGP stimulates wound contraction and accelerates healing. This may be due to the ability of WGP to enhance the functions of macrophages and myeloid hematopoietic cells, resulting in increased fibroblast division, collagen synthesis, and production of blood cells during wound healing.
\end{abstract}

Keywords: Panax ginseng, Wound healing, Ginseng, Polysaccharides, Fibroblast, Hydroxyproline, Collagen

Tropical Journal of Pharmaceutical Research is indexed by Science Citation Index (SciSearch), Scopus, International Pharmaceutical Abstract, Chemical Abstracts, Embase, Index Copernicus, EBSCO, African Index Medicus, JournalSeek, Journal Citation Reports/Science Edition, Directory of Open Access Journals (DOAJ), African Journal Online, Bioline International, Open-J-Gate and Pharmacy Abstracts

\section{INTRODUCTION}

The skin plays a crucial role in maintaining homeostasis. Wounds are breaks in the epithelial integrity of the skin, and may result in disruption of the structure and function of the underlying normal tissue, as well as other complications, including bacterial infections and fluid loss. Therefore, continuity of the skin must be expeditiously restored [1]. Wound healing involves a dynamic, well-orchestrated series of events that involves many different types of cells and inflammatory mediators such as cytokines [2,3]. Macrophages are essential for the transition from the inflammation to repair phases, and help orchestrate fibroblast proliferation and the removal of fibrin. Macrophages also secrete tumor necrosis factors (TNFs), which stimulate both fibroblasts and keratinocytes [4]. Fibroblasts proliferate and produce matrix proteins, including collagen, which help construct a new extracellular matrix that supports further ingrowths of cells and is essential for the repair process. Wound contraction occurs via an 
interaction between fibroblasts and the surrounding extracellular matrix [3].

Polysaccharides from plant extracts are important macromolecules that have been used as therapeutic agents in both animals and humans. In traditional medicine, polysaccharidecontaining plant extracts are widely employed for the treatment of skin and epithelium wounds and mucous membrane irritation [5]. Ginseng has been used for more than 2000 years, and is generally considered a longevity medicine [6]. Chinese traditional medicine textbooks describe its ability to tonify blood, expel toxins, promote skin regeneration, prevent infections, and regulate the immune system, among other actions [7-11]. Ginseng extracts have also been used clinically as a topical treatment for atopic suppurative dermatitis, wounds, and skin inflammation. Ginseng polysaccharides are major active components of ginseng [12,13]. Numerous studies on the pharmacology of WGP have shown that they induce the secretion of TNFs, enhance the activity of $T$ cells $[12,14]$, increase the function of mononuclear phagocytes, and promote the transformation of mononuclear phagocytes into macrophages [15]. WGP also play an important role in regulating the proliferation and differentiation of myeloid hematopoietic cells, which may be related to increases in hepatocyte growth factor (HGF) secreted by stromal cells in hematopoietic microenvironments to promote the production of blood cells [16,17]. However, studies on the effects of WGP on wound repair are lacking.

Therefore, we investigated the effects of WGP on the healing of full-thickness skin wounds in mice, as well as collagen deposition and the mechanisms by which WGP promote healing.

\section{EXPERIMENTAL}

\section{Materials}

WGP was prepared according to a previously reported method [18]. Dry ginseng root was heated in distilled water at $100{ }^{\circ} \mathrm{C}$ for $3-4 \mathrm{~h}$. The extract filtrate was condensed in a rotary evaporator and mixed with cold absolute ethanol. The polysaccharide precipitates were collected from the alcohol phase by centrifugation (4500 rpm, $10 \mathrm{~min})$. To obtain a pure product, the polysaccharides were deproteinized using Sevag reagent (n-butanol:chloroform $=1: 4$ ), starches were removed using a-amylase, and the polysaccharides were precipitated with $75 \%$ ethanol. After dialysis using distilled water, followed by lyophilization, WGP was obtained consisting of $84.4 \%(\mathrm{w} / \mathrm{w})$ sugar and $34.6 \%$ $(\mathrm{w} / \mathrm{w})$ uronic acid. The monosaccharide component consisted of $41.2 \%$ galacturonic acid, $20.1 \%$ galactose, $16.1 \%$ glucose, $15.8 \%$ arabinose, $2.7 \%$ rhamnose, and $2.2 \%$ mannose. Before using them, they were prepared as gels by dissolving $15 \mathrm{mg}$ or $30 \mathrm{mg}$ lyophilized powder in $0.1 \mathrm{~mL}$ distilled water. mEGF was purchased from Sigma Co., USA. Paraffin was kindly provided by Leica. Co. Ltd., Germany. A hydroxyproline assay kit was purchased from Sigma Co., USA. Slide glass was supplied by Matsunami, Japan. All chemicals and solvents were of analytical grade.

\section{Animals}

Forty male and female ICR mice weighing 28-32 $g$ were provided by the Animal Center of Jilin University. Animals were acclimatized for a week in a room with a controlled temperature of $23 \pm 2$ ${ }^{\circ} \mathrm{C}$ and a relative humidity of $30-60 \%$, and given free access to standard laboratory diet and water prior to the investigation. All animal experiments were approved by the Animal Experimental Ethics Committee of Northeast Normal University (approval ref no. 20130110) and carried out in strict accordance with the recommendations in the Guide for the Care and Use of Laboratory Animals of the National Institutes of Health [19].

\section{Excision wound model}

The mice were divided into four groups of forty animals: group 1 was the control, and groups 24 were treated with WGP $(15 \mathrm{mg})$, WGP $(30 \mathrm{mg})$, or mEGF $(0.1 \mathrm{~mL}, 2000 \mathrm{IU} / \mathrm{mL})$, respectively. The animals were anesthetized with ether, the dorsal hair was clipped, and one full-thickness, round wound about $9 \mathrm{~mm}$ in diameter was created on the back of each mouse using a sharp pair of scissors and a scalpel. Then WGP was applied to the wounds at a dose of $15 \mathrm{mg}$ or $30 \mathrm{mg}$. The control wound was treated with sterile cotton gauze during the postoperative period. After surgery, the animals were kept individually in separate cages. The progressive changes in wound area were measured in $\mathrm{mm}^{2}$ by tracing the wound boundaries on a plastic sheet every other day. Tracings were digitized by scanning and wound areas were quantified using Image $\mathrm{J}$ software. Wound contraction was expressed as the percentage reduction in wound size, as formulated in Eq 1.

$P_{W}=\left\{\left(S_{0}-S_{N}\right) / S_{0}\right\} \times 100$

where $P_{w}$ is the percentage of wound contraction, $\mathrm{S}_{0}\left(\mathrm{~mm}^{2}\right)$ is the primary wound area, 
and $\mathrm{S}_{\mathrm{N}}\left(\mathrm{mm}^{2}\right)$ is the wound area on day $\mathrm{N}$.

\section{Biochemical assays}

Collagen is an important component of wound healing, as it fills in tissue defects. Hydroxyproline exists almost exclusively in collagen [18] and thus is a sensitive biochemical marker that reflects changes in collagen fibers. Concentrations of hydroxyproline and collagen were estimated using the traditional acid hydrolysis method [20,21]. Excised granulation tissues were weighed, defatted in a chloroform:methanol mixture $(2: 1, \quad \mathrm{v}: \mathrm{v})$, hydrolyzed in $6.0 \mathrm{~N} \mathrm{HCl}$ for $6 \mathrm{~h}$ at $110^{\circ} \mathrm{C}$, and evaporated to dryness. The hydrolysate was neutralized to $\mathrm{pH} 6.0-6.8$ and subjected to chloramine-T oxidation. Then the test tubes were placed in a water bath at $60^{\circ} \mathrm{C}$ for $25 \mathrm{~min}$. The reaction was terminated by adding $1 \mathrm{~mL}(0.4 \mathrm{M})$ perchloric acid, the color was developed by adding $1 \mathrm{~mL}$ paradimethyl aminobenzaldehyde (PDAB), and the assay was read at $557 \mathrm{~nm}$ using a spectrophotometer. The collagen content was estimated from the hydroxyproline concentration by multiplying by 7.51 [20].

\section{Histological examination}

Skin including the wound was carefully excised $1,3,7$, and 10 days after injury and fixed in $4 \%$ formaldehyde, embedded in paraffin, and cut in 4-6 $\mu \mathrm{m}$ increments with a microtome. The sections were made perpendicular to the anterior-posterior axis and perpendicular to the surface of the wound. The sections were positioned on a slide, and stained with hematoxylin-eosin (HE) reagent. Representative sections from each wound were quantitatively evaluated for wound width, wound cellularity, neovascularization, and tissue granulation.

\section{Statistical analysis}

All data are expressed as mean \pm SD. Statistical analyses were performed using one-way ANOVA (SPSS Statistics 17.0). Differences were considered significant when $p<0.05$.

\section{RESULTS}

\section{In vivo observation}

There was no mortality in the study. In vivo observations were limited to injured lesions, body weight, and diet. The lesions resulted in local redness and swelling and moist fluid exudation from the subcutaneous tissues and wound edges in both the control and study groups. Three days after surgery, wounds treated with WGP/EGF had no effusion and new granulation had begun to cover part of the wound, while the control wounds still had some effusion and no granulation (Figure 1). WGP/EGF treatment considerably decreased inflammatory cells in the early phase of healing. There were no differences in body weight or diet between the control and study groups.

\section{Healing time, wound area, and wound contraction}

To evaluate the effects of WGP on wound healing, healing time and closure were observed. Healing time was significantly slower in controls than in the treatment groups (Table 1). WGP treatment accelerated wound contraction and shortened the healing time by 2-3 days. In addition, by day 7 , wounds treated with $30 \mathrm{mg}$ WGP had more epithelial tissue than the controls (Figure 1).

Table 1: Mean healing time of wounds $(n=10)$

\begin{tabular}{lc}
\hline Group & Wound healing time (day) \\
\hline 1 & $16.2 \pm 1.69$ \\
2 & $13.7 \pm 2.11^{\circ}$ \\
3 & $13.1 \pm 1.51^{\text {^ }}$ \\
4 & $12.6 \pm 3.23^{\text {^ }}$
\end{tabular}

Values are mean $\pm S D(n=10) ; p<0.05^{* * *} p<0.01$ $p<0.001$

As shown in Figure 2, treatment of wounds with $15 \mathrm{mg}$ and $30 \mathrm{mg} \mathrm{WGP}$ resulted in a higher rate of wound contraction, and the $30 \mathrm{mg}$ WGP group showed a faster closing rate. The rate of wound contraction in control mice was 30.2 to $42.2 \%$ from day 3 to day 7 and 65.8 to $85.3 \%$ from day 10 to day 14; complete epithelialization and healing were observed on day 16 . Mice treated with $30 \mathrm{mg}$ WGP showed increased wound contraction from $40.5 \%$ on day 3 to $57.4 \%$ on day 7 and 85.0 to $95.0 \%$ from day 10 to day 14 . Complete epithelialization and healing were observed on day 13. The percent of wound contraction in mice treated with mEGF was 49.3 $\%$ on day $3,66.4 \%$ on day 7 , and $85.1 \%$ on day 10 to $98.3 \%$ on day 14 , which was similar to the $30 \mathrm{mg}$ WGP group. 


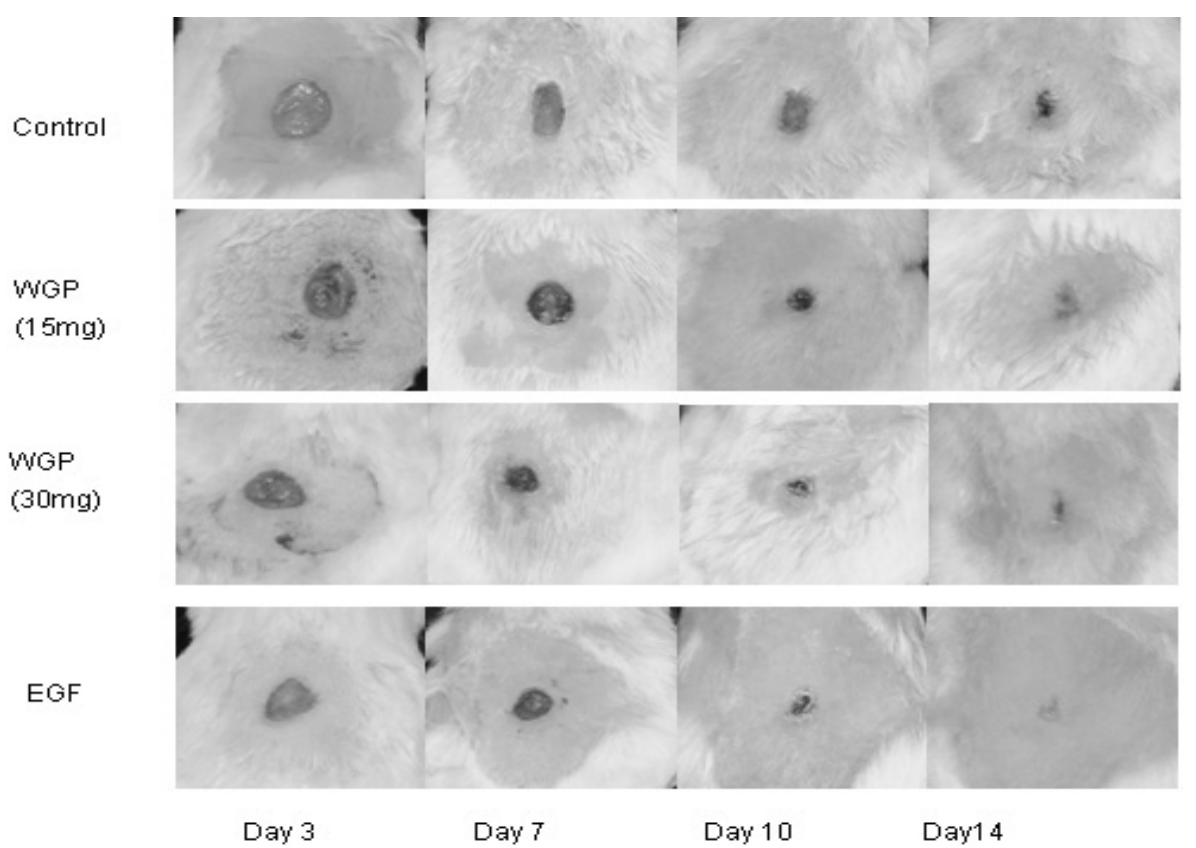

Figure 1: Photographic representation of a wound contraction area on different post-excision days in each group of mice at $3,7,10$, and 14 days post-injury

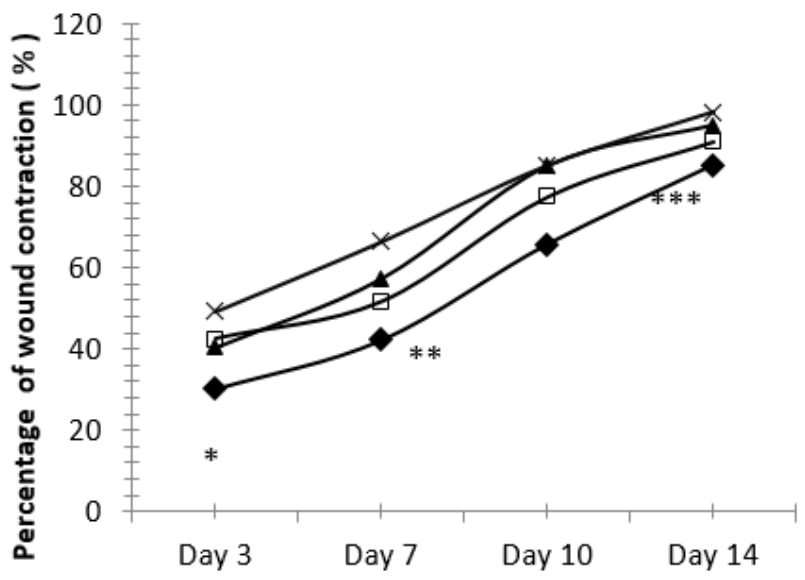

Figure 2: Effect of different doses of WGP on the contraction percentage of a full-thickness wound in mice. Data are given as mean \pm SD for 10 animals in each group. Statistically significant results are indicated as ${ }^{*}$ at $p<$ $0.05 ;$ control $=\diamond ;$ WGP $(15 \mathrm{mg})=\square ; \mathrm{WGP}(30 \mathrm{mg})=\boldsymbol{\Delta} ; \mathrm{EGF}=\times$

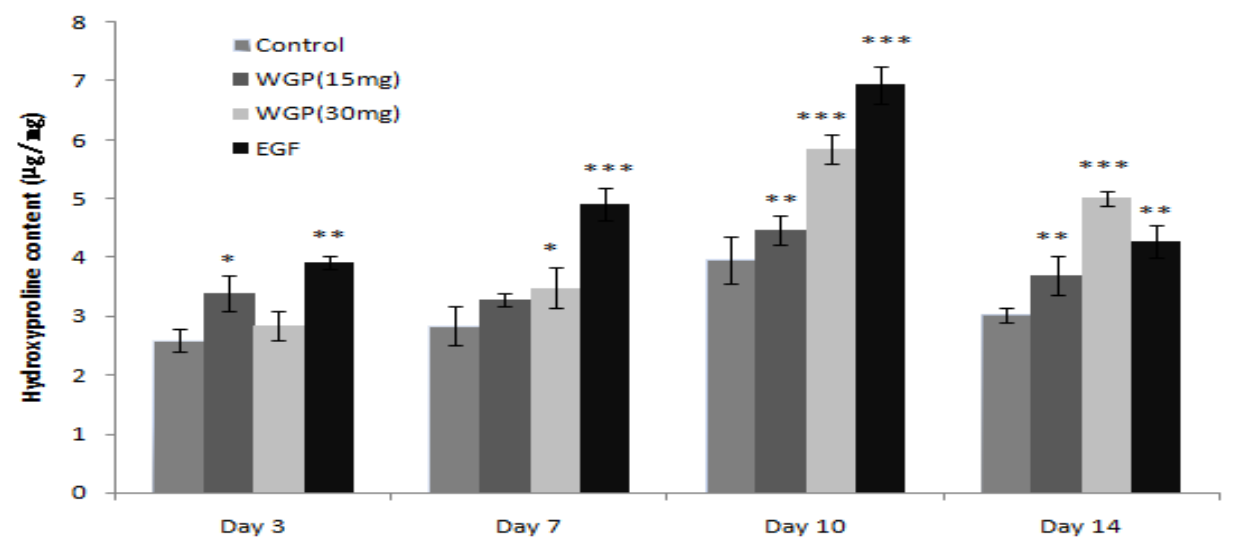

Figure 3. Effects of topical WGP on hydroxyproline content at 3, 7, 10, and 14 days post-injury. Values are mean \pm SD. ${ }^{*} P<0.05,{ }^{* *} P<0.01,{ }^{* * *} P<0.001$ 

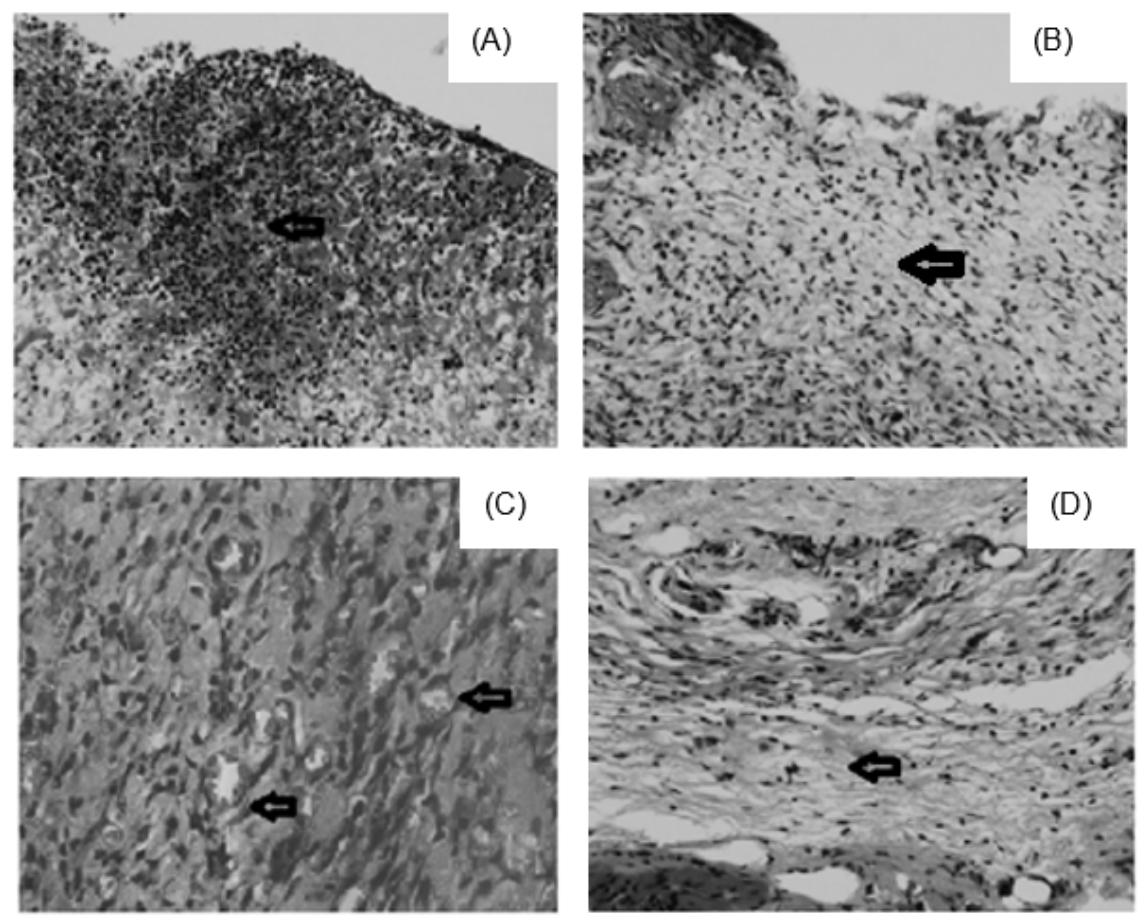

Figure 4. Histopathology of wounds stained with H\&E (100x). (A) WGP-treated mice showing large amounts of inflammatory cells (black arrow) on day 1. (B) Control mice showing a small number of inflammatory cells on day 1. (C) WGP-treated mice showing neovasculature and new blood cells in granulation tissue (black arrow) on day 3. (D) WGP-treated mice showing large amounts of granulation tissue, a small number of inflammatory cells, and extensive fibrosis (black arrow) on day 7

\section{Biochemical profile}

Figure 3 presents changes in collagen content. The maximum concentration of collagen in wounds from all groups was observed on day 10 post-injury. Both concentrations of WGP resulted in a significantly higher level of collagen compared to controls at all time points $(p<0.01)$. Then the concentration gradually decreased from day 10 and returned to the level recorded on day 7 in all experimental groups. However, the wounds from animals in groups 2 and 3 , which were treated with WGP, had a higher level of collagen than those in group 1 throughout the treatment $(p<0.05$, Figure 3$)$.

\section{Histological features}

Histological examination of wounds supported the observation that WGP accelerated healing. A significant increase in inflammatory cell infiltration and macrophage phagocytosis was found in WGP-treated wounds compared to control wounds after 1 day (Figure 4A,B). Skin wounds treated with WGP showed better healing than control mice, including observable granulation and the formation of a stratified epithelium (Figure 4D). Furthermore, neovasculature in granulation tissue progressed faster in WGP-treated mice compared to control mice (Figure 4C). By day 10 after injury, WGPtreated wounds were almost completely epithelialized and almost all necrotic tissues had been replaced by new granulation. The wounds were well protected and firmly covered with scabs.

\section{DISCUSSION}

We evaluated the wound-healing potential of WGP applied to full-thickness wounds in mice. Numerous studies have shown that the topical application of WGP can stimulate wound contraction and improve healing [23,26-28]. We found that the application of $15 \mathrm{mg}$ or $30 \mathrm{mg}$ WGP induced significant wound healing from days 3 to 14 after injury compared to the control group. Wound closure in the $30 \mathrm{mg}$ WGP group was similar to that in the EGF-treated group, and healing was significantly higher than in controls (40.5 vs. $30.2 \%, 57.4$ vs. $42.2 \%, 85.0$ vs. 65.8 $\%$, and 95.0 vs. $85.3 \%$ on days $3,7,10$, and 14 , respectively). The maximum difference between the WGP groups and controls was recorded 10 days after injury (Figure 2). Healing time was also shorter in WGP-treated mice than in controls. Together, these results suggest that WGP can accelerate wound contraction, and that higher doses have a stronger effect. 
The healing process begins with cell proliferation. The main cells that trigger the process are macrophages that remove foreign bodies and direct the development of granulation tissue. Then fibroblasts and endothelial cells migrate towards the injured area, increasing tissue permeability and the production of collagen fiber [22]. Wound contraction occurs through the interaction between fibroblasts and the surrounding extracellular matrix. Histological examinations confirmed that fibroblasts were abundant 3 days after injury in the WGP-treated groups. During the phase in which fibroblasts are attracted to the wounds, angiogenesis occurs from blood vessels near the injury. In WGPtreated groups, new blood vessels and soft, pink granulation tissue were well established. In contrast, in the control group, fibroblast cell proliferation was slow and new blood vessels and granulation tissue were not obvious 3 days after injury. These effects may be due to the increase in HGF secretion from stromal cells induced by WGPs in the hematopoietic microenvironment, which promotes the development of blood cells [13]. HGF is a key growth factor involved in wound healing, and it plays an important role in neovascularization and the formation of granulation tissue [1]. These findings suggest that WGP accelerate wound closure in mice to a similar extent as EGF.

Three days post-injury, control wounds were obviously red and swollen, with inflammatory exudation. In contrast, WGP-treated wounds were almost completely dry and covered with granulation tissue with no obvious swelling (Figure 1) [2]. These results suggest that WGP can increase the function of the mononuclear phagocyte system [14], which is an important process in wound healing. In the early phases of wound healing, monocytes are recruited to the wound by growth factors, and monocyte chemoattractant proteins adhere to the provisional fibrin plug matrix via integrin receptors before transforming into macrophages. Macrophages perform phagocytosis to destroy invading bacteria and clear debris and necrotic tissue [3]. Therefore, WGP treatment decreased the inflammatory response at the wound site (Figure $4 A)$. This effect could also be related to the antimicrobial traits of WGP $[20,22]$.

Hydroxyproline is an amino acid that is essential for the synthesis of collagen fibers. For this reason, its levels are used as an indicator of collagen content. Hydroxyproline levels in granulation tissues increased in all treatment groups from days 3 to 10 , and then returned to day 7 levels by day 14 (Figure 3) [24-26].

\section{CONCLUSION}

Application of WGP to open wounds induces significant wound contraction and accelerated closure and healing in mice. These results lend some support to the traditional use of ginseng root to treat skin diseases. However, more work is required to unravel the possible mechanisms involved in the process of wound healing, whether it is by regulating the body's immune system or by direct action on the wound.

\section{DECLARATIONS}

\section{Acknowledgement}

The authors acknowledge Northeast Normal University for financial support to carry out the work. We thank MS Pan (pathology Laboratory, Jilin University) for the facilities provided and technical support

\section{Conflict of Interest}

No conflict of interest associated with this work.

\section{Contribution of Authors}

The authors declare that this work was done by the authors named in this article and all liabilities pertaining to claims relating to the content of this article will be borne by them.

\section{Open Access}

This is an Open Access article distributed under the terms of the Creative Commons Attribution License, which permits unrestricted use, distribution, and reproduction in any medium, provided the original work is properly credited.

\section{REFERENCES}

1. Sinha $R$, Singh $N$, Kumar V. Pathophysiology of Wound Healing. LAP Lambert Academic Publishing 2013: 1-5.

2. Williamso D, Keith H. Wound healing. Basic. Sci. Med. 2004; 32: 4-7.

3. Stuart E, David J. Basic science of wound healing. Basic. Sci. Surg. 2007; 26: 31-37.

4. Sadaf $F$, Saleem $R$, Ahmed M, Ahmad S, Navaid U. Healing potential of cream containing extract of sphaeran thus indicus on dermal wounds in Guinea pigs. J. Ethnopharmacol. 2006; 107: 161-163.

5. Basak MK, Shenefelt PD. Herbal therapy in dermatology. Arch Dermatol 2002; 138: 232-242.

6. Divine SN. Farmer's Classic of Material Medical. 2015: 18.

Trop J Pharm Res, November 2016; 15(11): 2404 
7. Lee FC. Facts about Ginseng, the Elixir of Life. Hollyn. International. Corp., Elizabeth, NJ, 1992: 45-47.

8. Huang KC. The Pharmacology of Chinese Herbs. CRC Press, Boca Raton, FL, 1999: 101-104.

9. Lim $T$, Na K, Choi E, Chung J, Hwang J. Immunomodulating Activities of Polysaccharides Isolated from Panax ginseng. J. Med. Food 2004; 7: 1-6.

10. Ahn J, Choi I, Shim J, Yun E, Yun Y, Jeong G, Song J. The immunomodulator ginsan induces resistance to experimental sepsis by inhibiting Toll-like receptor mediated inflammatory signals. Eur. J. Immunol. 2006; 36: 37-45.

11. Ahn J, Song J, Yun Y, Jeong G, Choi I. Protection of Staphylococcus aureus-infected septic mice by suppression of early acute inflammation and enhanced antimicrobial activity by ginsan. FEMS Immunol. Med. Microbial. 2006; 46: 187-197.

12. Assinewe VA, Amason JT, Aubry A, Mullin J, Lemaire I. Extractable polysaccharides of Panax quinquefolius $L$. (North American ginseng) root stimulate TNF alpha production by alveolar macrophages. Phytomedicine 2002; 9: 398-404.

13. Zhang YS, Li RQ, Wang WY. Research on panax ginseng polysaccharide. J Northeast Norm Univ 1982; 22: $97-100$.

14. Kim K, Lee Y, Jung I. Acidic Polysaccharide from Panax ginseng, Ginsan, Induces Th1 Cell and Macrophage Cytokines and Generates LAK Cells in Synergy with rlL2. Planta. Med. 1998; 64: 110-115.

15. Sun YX. Structure and biological activities of the polysaccharides from the leaves, roots and fruits of Panax ginseng C. A. Meyer: An overview. Carbohydr. Polym. 2011; 85: 490-499.

16. Da Q, Wang YP, Zhou KZ, Jiang R, Wu H, Zheng M. The effect of ginseng polysaccharide on proliferation of human promyelocytic leukemia cell line (HL-60). J. Chongqing Med. Univ. 2001; 26: 126-131.

17. Ahn J, Choi I, Shim J. The immunomodulator ginsan induces resistance to experimental sepsis by inhibiting Toll-like receptor mediated inflammatory signals. Eur. J. Immunol. 2006; 36: 37-45.
18. Zhang $X, Y u$ L, Bi HT, Li XH, Ni WH, Han H, Li N, Wang $B Q$, Tai GH, Zhou YF. Total fractionation and characterization of the water-soluble polysaccharides isolated from Panax ginseng C. A. Meyer. Carbohydr. Polym. 2009; 77: 544-552.

19. National Institute of Health. USA. Public health service policy on human care and use of laboratory animals, 2002.

20. Miller EJ, Martin GR, Piez KA. The utilization of lysine in the biosynthesis of elastin crosslinks. Biochem. Biophys. Res. Commun. 1964; 17: 248.

21. Ni WH, Zhang $X$, Wang B. Antitumor activities and immunomodulatory effects of ginseng neutral polysaccharides in combination with 5-fluorouracil. J. med Food. 2010; 13: 270-277.

22. Balbino CA, Pereira LM, Curi R. Mecanismos envolvidos na cicatrizacao: uma revisao. Brazil. J. Pharmacl. Sci. 2005; 41: 27-51.

23. Lloyd LL, Kennedy JF, Methacanon P, Paterson M, Knill CJ. Carbohydrate polymers as wound management aids. Carbohydr. Polym. 1998; 37: 315-322.

24. Leibovich SJ, Ross R. The role of the macrophage in wound repair: a study with hydrocortisone and antimacrophage serum. Am. J. Pathol. 1975; 78: 71100.

25. Ichiro O, Hironori G, Zhang JZ. Studies on cytokines related to wound healing in donor site wound fluid. J. Dermatol. Sci. 1995; 10: 241-245.

26. Deng CM, He LZ, Zhao M, Yang D, Liu Y. Biological properties of the chitosan-gelatin sponge wound dressing. Carbohydr. Polym. 2007; 69: 583-589.

27. Wang R.X, Matthias L, Jandirk S, Frank P, Alexandra D, Andreas $H$. Wound-healing plants from TCM: in vitro investigations on selected TCM plants and their influence on human dermal fibroblasts and keratinocytes. Fitoterapia 2013; 84: 308-317.

28. Mohammad RT, Ahmad O, Adel M. Polysaccharides of Aloe vera induce MMP-3 and TIMP-2 gene expression during the skin wound repair of rat. Int. J. Biol. Macromol. 2014; 65: 424-430. 